\title{
The Foreign Labor Increase Impact on the Wages of Local Residents: From the Perspective of City Scale
}

\author{
Hui Pang ${ }^{1}$ and Mi Zhou ${ }^{2}$ \\ ${ }^{1}$ College of Economics; Shenyang University, Shenyang China \\ ${ }^{2}$ College of Economics and Management; Shenyang Agricultural University, Shenyang China
}

\begin{abstract}
CGSS2008 data and found that the influence was not significant for the local residents on migrant labors flowing, while the migrant workers increased by $1 \%$, the annual wage income of residents in provincial city increase $1.46 \%$, but fell $0.83 \%$ in small and medium-sized city. Therefore, the relationship between migrants and local residents is complementary effect and substitution effect coexist at the same time in mega-cities, the complementary effect is stronger than substitution effect in big city (like Provincial capital) and the substitution effect is stronger than the complementary effect in small and medium-sized city.
\end{abstract}

\section{Introduction}

The floating population of the city bring what kind of influence to the local labor market in China, which plays an important role in the formulation and management policy of floating population and has been the government and academic's focuses. With the development of our economy and the accelerated process of industrialization, city needs a large number of migrant workers to improve the level of city in China. However, some scholars believe that the big city is easy to realize economic agglomeration that have priority to the development (Wang and Xia , 1999).Others think that giving priority to the development of small towns can make a large number of farmers to become rapidly nonagricultural rural labors, reducing the settlement city psychological cost and the construction funds that are more in line with the Chinese conditions (Xiao, 2009). Especially the government introduced the relevant measures in the February 23, 2012. The statement is "small and medium-sized city in the future requirements of regulations on employment, education, skills training and other policy measures, and do not account for the nature of the Hukou. Continue to explore the establishment of a unified urban and rural household registration system". This suggests settlement cost of the rural labor force in small and medium-sized city will reduce. Furthermore, do immigration city scale on different rank affect the labor consistent? This study has very important realistic significance, which will help building of new towns in China and promote the orderly transfer of population urbanization.

\section{Theories and Methods}

Corresponding author: dhtzor@gmail.com
We assumes that under different scales cities, Labour supply rate of floating population on different levels of education and work experience can be used as follows:

$$
p_{i j t}=M_{i j t} /\left(M_{i j t}+N_{i j t}\right)
$$

Among them, ${ }^{M_{i j t}}$ means foreign population, i level of education and work experience is $\mathrm{j}$ under the conditions of the $\mathrm{t}$ level urban size, $N_{i j t}$ is local population, $i$ level of education and work experience is $j$ under the conditions of the $\mathrm{t}$ level urban size. The following model is constructed to measure elastic wages: $y_{i j t}=\theta p_{i j t}+s_{i}+x_{j}+\pi_{t}+\left(s_{i} \times x_{j}\right)+$ $\left(s_{i} \times \pi_{t}\right)+\left(x_{j} \times \pi_{t}\right)+\varphi_{i j t}$

Among them, $S_{i}$ says the factors related to education level of labor force, ${ }^{x_{j}}$ says experience factors associated with the migrant population, ${ }^{\pi_{t}}$ means city scale related factors. According to Borjas (2003), we can get wage flexibility is derived as:

$$
\begin{gathered}
\frac{\partial \log w_{i j t}}{\partial m_{i j t}}=\frac{\theta}{\left(1+m_{i j t}\right)^{2}} \\
\text { In addition, } \\
m_{i j t}=M_{i j t} / N_{i j t}
\end{gathered}
$$

\section{Data}

In this paper, the data we use are from China General Social Survey 2008 open database (CGSS2008).The data 
are ranged by adopting stratified four stages unequal probability sampling: the district (county), the streets (town), residents' committees, temporary residents and residents, the district (county), street (town), the residents' committees/village, the three levels data have completed sampling based on "the fifth national population census data" (2000 census).Before the survey, temporary residents and residents (respondents) are sampled, and we get the sample of 6000, the city samples are 3982, 2018 rural samples. The data used in the study is the laborer sample data group by the education and experience from city to city.Therefore, we need to make some important concepts be defined, and select and process the samples, after processing the sample size are of 2452.

\section{Model and Results}

According to the calculation formula of wage elasticity, we using the weighted OLS to analyze the floating population's influence on local residents incomes under different size cities. The results of the analysis as shown in table 1.

Table 1 The floating population wage replacement of local residents under different urban size

\begin{tabular}{|c|c|c|c|c|}
\hline \multirow{2}{*}{ lwagen } & $(1)$ & $(2)$ & $(3)$ & $(4)$ \\
\cline { 2 - 5 } & city & City=1 & City=2 & City=3 \\
\hline \multirow{2}{*}{ pi } & $0.537^{*}$ & -0.221 & $2.672^{* * *}$ & $-1.609^{* *}$ \\
\cline { 2 - 5 } & $(0.311)$ & $(0.435)$ & $(0.465)$ & $(0.590)$ \\
\hline $\begin{array}{c}\text { wage } \\
\text { elasticity }\end{array}$ & 0.27 & -0.08 & 1.46 & -0.83 \\
\hline
\end{tabular}

Note: (1) in parentheses are standard deviations, $* * * \mathrm{p}<0.01$, ${ }^{* *} \mathrm{p}<0.05,{ }^{*} \mathrm{p}<0.1 ;(2)$ due to the limitation of space, there is no report all regression variables as a result, other explanatory variables including edu, exp_1, city, edu * exp_1, edu * city, exp_1* city;(3) the regression results reported in the table for different cities under each type of level of education and work experience $(i, j)$ set of sample size for the results of the weight.

$$
\begin{aligned}
& \text { According to the salary elasticity } \\
& \frac{\partial \log w_{i j t}}{\partial m_{i j t}}=\frac{\theta}{\left(1+m_{i j t}\right)^{2}} \text {, we can calculate the wage }
\end{aligned}
$$
formula $\partial m_{i j t}\left(1+m_{i j t}\right)^{2}$, we can calculate the wage elasticity of substitution of local citizens about 0.27 $(0.537 * 0.5)$, suggest that a $10 \%$ increase in labor supply can make local people salary increase $2.7 \%$.In different cities this effect is not consistent, in the three largest cities, floating population has no significant impact on local people wage replacement, and the elasticity of substitution is very small, a $10 \%$ increase in labor supply, the salary of local residents reduce only $0.8 \%$; Level in the provincial capital cities, floating population has significant positive influence on improving the salary for local citizens , a 10\% increase in Labour supply, the local people salary will increase $14.6 \%$; In small and mediumsized cities, the labor supply increase $10 \%$ will make local people salary decline $8.3 \%$.Therefore, the relationship between the migrants and local residents are complementary. In order to further investigate whether wages substitution effect is from a particular group or not, this article analyzes the different levels of education and work experience, and get wage elasticity between different education - experience - city group of floating population and the citizens (as shown in table 2).

Table 2 shows, all floating workers in city group with college degree and high school diploma of have significantly improved the level of wages, although the workers who have a junior high school degree and higher vocational education reduces the local citizens incomes, but the impact is not significant. In different size cities, the effect are the most obvious in the provincial capital city, There have no significant impact on urban and small and medium-sized cities.In table 2 the column from (5)to- (8) means the impact on wages from differences of experience.Overall, the floating population have more than 10 years working experience in the cities will significantly increase the wages of local residents, the effect no matter in any city size is consistent, and are only more obvious in the provincial capital cities. For parttime experiences less than 10 years is a negative influence on local residents income. Especially in urban, the increase of floating population will significantly reduce the wages of local residents, and form a trade-off among local residents.

Table 2 Education difference、 experience difference、

\begin{tabular}{|c|c|c|c|c|}
\hline & (1) & (2) & (3) & (4) \\
\hline & $E d u=1$ & $E d u=2$ & $E d u=3$ & $E d u=4$ \\
\hline \multirow{2}{*}{ city } & -0.466 & $1.220 * *$ & -0.131 & $1.561 * *$ \\
\hline & $(0.283)$ & $(0.509)$ & $(0.299)$ & $(0.723)$ \\
\hline \multirow{2}{*}{ City $=1$} & -1.625 & 0.825 & -0.250 & -0.336 \\
\hline & $(1.035)$ & $(1.059)$ & $(0.286)$ & $(1.619)$ \\
\hline \multirow{2}{*}{ City $=2$} & $-2.369 * *$ & -0.177 & -0.263 & $3.906 * * *$ \\
\hline & $(0.687)$ & $(0.486)$ & $(0.496)$ & $(0.765)$ \\
\hline \multirow{2}{*}{ City $=3$} & -1.993 & -1.403 & -2.299 & -1.731 \\
\hline & $(1.880)$ & (1.427) & (1.939) & $(1.018)$ \\
\hline & (5) & (6) & (7) & (8) \\
\hline & $\begin{array}{c}\operatorname{Exp}_{-} 1=1 \\
2\end{array}$ & $\begin{array}{c}\text { Exp_1 } 1=3, \\
4\end{array}$ & $\begin{array}{c}\text { Exp_1 }_{-}= \\
5,6\end{array}$ & $\begin{array}{c}\text { Exp_1 }=7, \\
8\end{array}$ \\
\hline & $-0.494 * *$ & $0.851 * *$ & $1.731 * *$ & 0.00955 \\
\hline & $(0.230)$ & $(0.310)$ & $(0.677)$ & $(0.783)$ \\
\hline & $-0.734 * *$ & $0.770^{*}$ & $1.704 *$ & 0.0561 \\
\hline & $(0.305)$ & $(0.368)$ & $(0.864)$ & $(0.860)$ \\
\hline & 0.402 & $1.056^{* * *}$ & $2.585 * *$ & 0.538 \\
\hline & $(0.375)$ & $(0.342)$ & $(0.722)$ & $(0.770)$ \\
\hline & 0.388 & $0.999 * * *$ & $2.104 * *$ & 0.193 \\
\hline & $(0.405)$ & $(0.318)$ & $(0.845)$ & $(0.850)$ \\
\hline
\end{tabular}
and wage elasticity

Note: (1) that in parentheses are standard deviations, ${ }^{* * *} \mathrm{p}<0.01$, ${ }^{* *} \mathrm{p}<0.05, * \mathrm{p}<0.1 ;(2)$ the regression results in the table above 
reports for different cities take the sample size of different levels of education and the different working experience as the weight.

\section{Conclusion and Discussion}

In this paper, the research found that Labour mobility under different urban size have different effects on the local Labour market.In the three largest cities, flow labor have no significant impact on local residents incomer; In the other provincial capital cities, the increase of foreign labor will significantly increase the wages of local residents; While in small and medium-sized cities, will reduce the wages of the local people. The reason is that the extra large city scale expanding, the floating labors' alternative cause labor consumption, and ease the citizens' wage changes;And in the provincial capital cities, floating population promote the regional industrial division, strengthen the foreign labor cooperation with local citizens, at the same time, also improve the wage level of the local people;But, in small and medium-sized cities, because of the low labor heterogeneity degree, the competitive relationship between migrants and local residents reduce the wages of the local residents.

\section{Acknowledgements}

This work was supported by the National Science Foundation of China(NO.71203146; NO.71273179; NO.71373163; NO.71273177), the program for excellent talents in Liaoning province(NO.WJQ2014016); and agriculture youth science and technology innovation talent training plan in Liaoning province(NO.2014055).

\section{References}

1. Xue-jun Liu, Yao-hui Zhao. Labor flow's influence on urban labor market [J]. Economics (quarterly), 2(2009)

2. Ming Lu, Hong Gao, Hong Sato . Urban scale and inclusive employment [J]. Chinese academy of social sciences, 10(2012).

3. Xiao-han Zhong . Labour mobility and wage differences $[\mathrm{J}]$. Chinese academy of social sciences, 1 (2006).

4. Aydemir A.,Borjas G.J. Cross - country Variation in the Impact of International Migration: Canada, Mexico, and the United States[J],Journal of the European Economic Association,5(4)(2007):663-708.

5. Borjas G.J. The Labor Demand Curve Is Downward Sloping: Reexamining the Impact of Immigration on the Labor Market[J], The Quarterly Journal of Economics, 118(4)(2003):1335-1374. 